\title{
$1 N \cdot 44$
}

NASA Technical Memorandum 106228

\section{P. 6}

\section{Non-Destructive, Ultra-Low Resistance, Thermally Stable Contacts for Use on Shallow Junction InP Solar Cells}

V.G. Weizer

National Aeronautics and Space Administration

Lewis Research Center

Cleveland, Ohio

N.S. Fatemi

Sverdrup Technology, Inc.

Lewis Research Center Group

Brook Park, Ohio

and

(NASA-TM-106228) NON-DESTRUCTIVE,

N93-32201 ULTRA-LOW RESISTANCE, THERMALLY

A.L. Korenyi-Both STABLE CONTACTS FOR USE ON SHALLOH

Calspan Corporation JUNCTION INP SOLAR CELLS (NASA)

Unclas

Cleveland, Ohio

$6 \mathrm{p}$

G3/44 0176659

Prepared for the

$=23$ rd IEEE Photovoltaic Specialists Conference

sponsored by the Institute of Electrical and Electronics Engineers

Louisville, Kentucky, May 10-14, 1993

\section{N/SN}


$\therefore \quad \Rightarrow+\cdots$

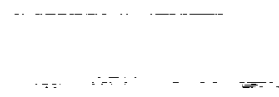

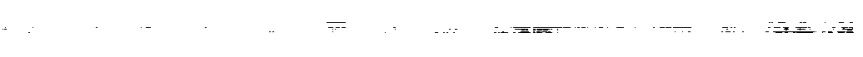


NON-DESTRUCTIVE, ULTRA-LOW RESISTANCE, THERMALLY STABLE CONTACTS FOR USE ON SHALLOW JUNCTION InP SOLAR CELIS

\author{
V.G. Weizer \\ National Aeronautics and Space Administration \\ Lewis Research Center \\ Cleveland, Ohio 44135
}

\author{
N.S. Fatemi \\ Sverdrup Technology, Inc. \\ Lewis Research Center Group \\ Brook Park, Ohio 44142
}

\author{
A.L. Korenyi-Both \\ Calspan Corporation \\ Cleveland, Ohio 44130
}

\section{ABSTRACT}

Contact formation to InP is plagued by violent metal-semiconductor intermixing that takes place during the contact sintering process. Because of this the InP solar cell cannot be sintered after contact deposition. This results in cell contact resistances that are orders of magnitude higher than those that could be achieved if sintering could be performed in a non-destructive manner. We report here on a truly unique contact system, involving $A u$ and $G e$, which is easily fabricated, which exhibits extremely low values of contact resistivity, and in which there is virtually no metal-semiconductor interdiffusion, even after extended sintering. We present a description of this contact system and suggest possible mechanisms to explain the observed behavior.

\section{INTRODUCTION}

The most common contact metallization systems in use on $n$-InP devices consist of yarious combinations of $\mathrm{Au}, \mathrm{Ge}$, and $\mathrm{Ni}$. (1-13) In order to secure optimum values of the contact resistivity $R_{c}$, these systems must be sintered at elevated temperatures after metal deposition. The sintering step, while reducing $R_{C}$, has the undesirable effect of inducing substantial metallurgical interdiffusion between the metallization and the InP substrate. This interdiffusion, unless carefully controlled by the imposition of diffusion barriers (14) or by the use of techniques such as rapid thermal annealing $(14,15)$, can quickly degrade or destroy the device being contacted. The solar cell and other shallow junction devices are most sensitive to these effects. For these devices especially, a trade-off must be made between contact performance and device integrity.

The degrading effects of contact sintering can be easily seen in the simple case of elemental Au contacts on $n$-InP. In this system, $R_{C}$ reduction during sintering is due to the formation of the compound $\mathrm{Au}_{2} \mathrm{P}_{3}$ at the metal-InP interface. ( 16$)^{2} \mathrm{Au}_{2} \mathrm{P}_{3}$ formation, however, does not take place immediately, rather it forms during the second of three stages that occur during the Au-InP sintering process. During the first stage of the reaction, prior to the formation of $\mathrm{Au}_{2} \underline{P}_{3}$, sufficient InP dissolves into the contacting $A U$ metallization to raise the In content in the Au lattice to the solid solubility limit (about 10 at 8 ). The phosphorus atoms released during this stage dissipate without reacting. Thus, before the resistivity begins to drop, there is a significant amount of metal-semiconductor intermixing. Similar interdiffusion problems have been shown to occur in the Ni-InP(1-3), the AuNi-InP $(11,12)$, and the AuGeNi-InP(1-5) systems. In these systems the formation of $\mathrm{Ni}$-based compounds at the metal-InP interface are responsible for the sinter-induced resistivity drops. (1I, 13) As in the case of Au-only contacts, extreme care must be taken to avoid cell degradation during contact formation.

In the course of an investigation into the mechanisms involved in the reactions of $\mathrm{Au}, \mathrm{Ge}, \mathrm{Ni}$, and various combinations of these with InP, we have discovered a contact system that provides extremely low contact resistivity, which is easily fabricated, and in which there is virtually no metal-semiconductor interdiffusion, even after extended sintering. The purpose of this paper is to describe this unique contact system, involving $A u$ and $G e$, and to suggest possible mechanisms that explain the observed behavior.

\section{EXPERIMENT}

The structures used in this investigation were all $\mathrm{n} / \mathrm{p}$ diodes with epitaxially deposited emitters, $2000 \mathrm{~A}$ thick, Si doped to $1.7 \times 1018 \mathrm{~cm}^{-3}$. The ( 100 ) oriented substrates were $\mathrm{zn}$ doped to $8 \times 1016 \mathrm{~cm}^{-3}$. Specific contact resistivity measurements were made using the transmission line method (TLM). Deposition of the contact metallization was done by electron beam evaporation. The samples were not actively cooled during deposition. Unless otherwise stated, the contact metals, $A u$ and $\mathrm{Ge}$, were deposited in a layered structure in the sequence: InP $/ 400 \mathrm{~A} \mathrm{Au} / 200 \mathrm{~A}$ Ge/1600 A $\mathrm{Au}$. While these contacts contain about 7 at Ge, we have found essentially the same results for InP/200 A AU/700 A Ge/ $1200 \mathrm{~A}$ Au ( 28 ats $\mathrm{Ge})$ contacts. 
Post-deposition sintering was performed in a rapid thermal annealing (RTA) apparatus that provides rise times of about 10 seconds with negligible overshoot. The ambient during sintering was nitrogen.

To monitor the degree of emitter dissolution/perforation caused by the sintering process, we observed the quality of the diode current-voltage $(I-V)$ characteristic. As a measure of the $I-V$ quality we arbitrarily defined a conduction voltage $V_{1}$ as the voltage at which the forward current through the TLM patternea diode (area $5.6 \times 10^{-3} \mathrm{~cm}^{2}$ ) is $1 \mathrm{~mA}$. (9) A good pn junction should exhibit a $V_{1}$ of about $900 \mathrm{mV}$. Lower values indicate a degraded emitter. Compositional analysis was performed via energy dispersive spectroscopy (EDS). To reveal subsurface detail for EDS analysis we used a thiourea-based $(16,17)$ chemical etch.

\section{LOW RESISTANCE, NON DESTRUCTIVE CONTACTS}

We have founo that the addition of small amounts of Ge to Au contact metallization has a significant effect on both the metallurgical and the electrical characteristics of those contacts. Figure 1 shows the variation of the specific contact resistivity during sintering at $350 \mathrm{C}$ for Au-only contacts and for $\mathrm{Au}$ contacts containing 7 at: Ge. The difference between the two samples is striking. Whereas the resistivity of the Au-only sample remains in the $10^{-3}$ ohm $\mathrm{cm}^{2}$ range for tens of minutes at $350 \mathrm{C}$, only 1 minute at that temperature is necessary to bring the resistivity of the Au-7 ats Ge sample down four orders of magnitude to the low $10^{-7}$ ohm $\mathrm{cm}^{2}$ range. These resistivities match the best reported values for any contact system on Inf and are ten times lower than those that can be

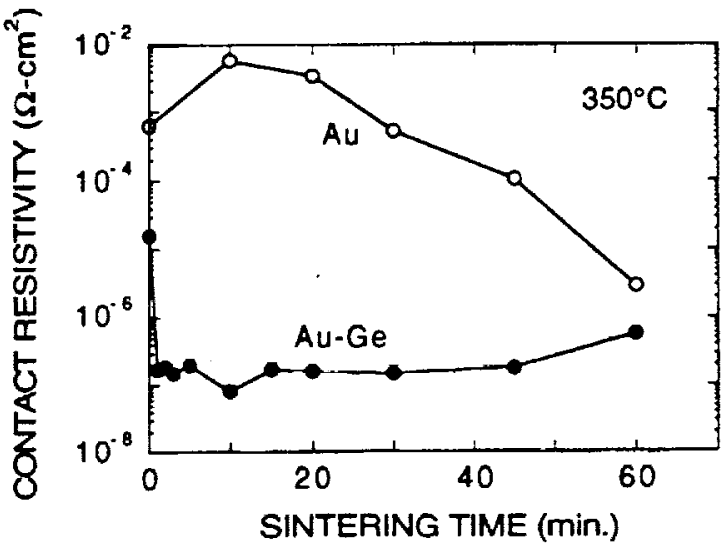

Figure 1. The variation of the specific contact resistivity with time during sintering at $350 \mathrm{c}$. achieved with Au-only contacts(9). Another, even more striking difference between the two types of contacts is illustrated in figure 2. The figure compares the sinter-induced variations in the conduction voltages for the Au-only and the $\mathrm{Au}-7$ at $\mathrm{Ge}$ contacted samples. While the value of $V_{1}$ for the Au-only contacted sample has dropped significantly after 30 minutes at $350 \mathrm{C}$, $v_{1}$ for the Au-7 at Ge sample remains unchanged under identical sintering conditions. Thus, even though the resistivity of the $\mathrm{Au}-7$ at $\mathrm{Ge}$ contacted sample has been drastically reduced by the sintering process, there is no evidence of any metal-semiconductor interdiffusion. Optimization of the contact resistivity has thus been achieved without compromising the integrity of the underlying device. This has never been seen before.

Further evidence that $G e$ additions retard Au-InP intermixing during sintering can be seen in the metallurgical data shown in figure 3 . We have shown in previous work that during the second stage of the Au-InP sintering process, concurrent with the formation of the $\mathrm{R}_{\mathrm{c}}$-reducing compound $\mathrm{Au}_{2} \mathrm{P}_{3}$ at the metal-InP interface, the pink colored compound $A u_{3} I n$ forms at the free surface of the metallization. (16) Figure 3 shows the percentage of the contact metal surface that has been converted to Aus In as a function of time at $350 \mathrm{C}$ for both the $A u-o n I y-$ and the $A u-7$ at $\mathrm{Ge}$ contacts. As can be seen the Au-only contacts begin to react almost

immediately, whereas Ge-containing contacts show no sign of reaction even after 45 minutes at that temperature. The addition of a small amount of $\mathrm{Ge}$ to Au-only contacts has thus enabled the achievement of $R_{C}$ values that are among the lowest reported, while at the same

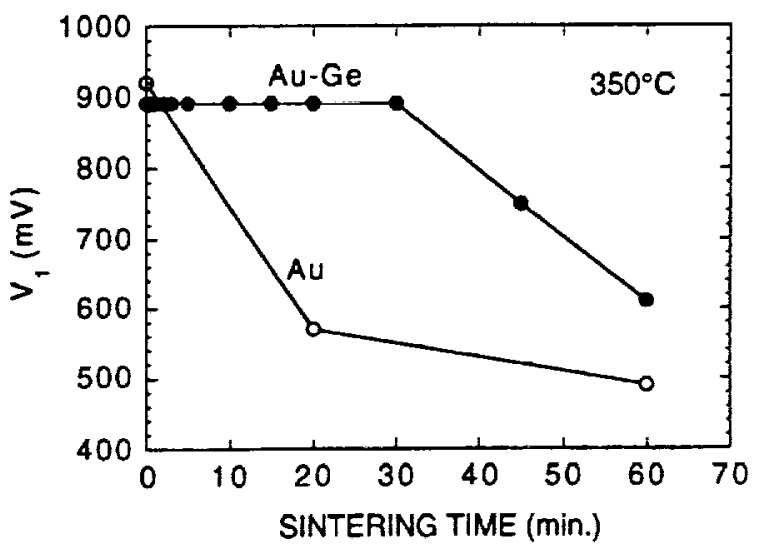

Figure 2. The variation of the conduction voltage with time during sintering at $350 \mathrm{C}$. 
time preventing the device-destroying metallurgical interactions that would normally occur during the sintering process.

\section{DISCUSSION}

As discussec above, the presence of $G e$ in $A u$ contact metallization retaras metal-InP intermixing during sintering. Similar reaction retarding (but not $R_{C}$ reducing) effects have been observed when small (several atomic percent) amounts of gallium are added to Au contacts on InP. (9) We know from previous work that the dissolution of InP into contacting $\mathrm{Au}$ metal takes place via a dissociative diffusion process. (16) In this process in atoms from the InP substrate enter the Au lattice interstitially and diffuse until encountering vacant sites in the Au lattice, at which point they enter the vacancies and take substitutional sites on the Au lattice.

It has been suggested that gallium, when added to the Au metallization, enters and saturates the interstices of the $\mathrm{Au}$ lattice, thereby preventing entry of interstitial In. (9) when in is prevented from entering the metallization, the Au-InP interdiffusion process comes to a halt. In the present case, with regard to the reaction retarding effects that accompany the addition of $\mathrm{Ge}$, we propose that a similar mechanism is involved. We propose that a portion of the added $\mathrm{Ge}$ atoms enter and saturate the interstices of the Au lattice, thereby suppressing metal-semiconductor interdiffusion. Given that $G e$ interstitial saturation retards metal-InP interdiffusion, the cause of the drastic drop in $R_{c}$ after only 1 minute at $350 \mathrm{C}$ remains to be explained. In an attempt to identify the mechanisms responsible for the low values of $R_{C}$, we subjected a number of $\mathrm{Au}-7$ at $8 \mathrm{Ge}$ contacted samples to a thiourea-based chemical etch which has

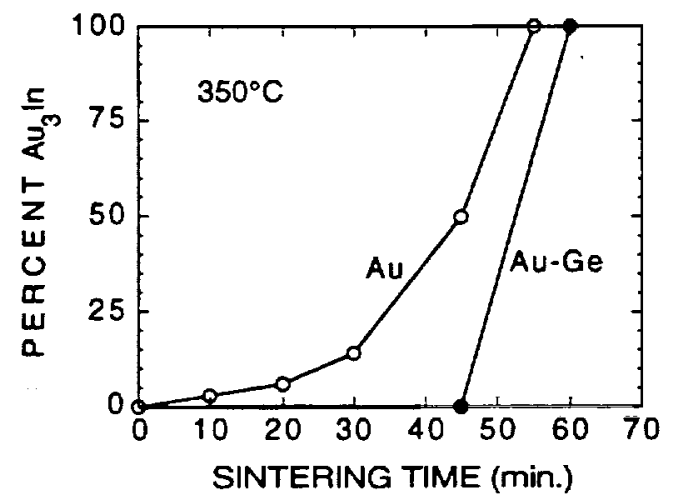

Figure 3. Percent Au-to-Au 3 In conversion as a function of time during sintering at $350 \mathrm{C}$. been shown to dissolve Au and Au-In alloys while doing negligible harm to the InP substrate. $(16,17)$ The samples that were etched had been sintered for 1 minute at either 350 or $400 \mathrm{C}$, and they showed $R_{C}$ values in the low $10^{-7} \mathrm{ohm}^{\mathrm{cm}}{ }^{2}$ range and $v_{1}$ values near $900 \mathrm{mV}$.

As shown in figure 4 , the etching process exposed a tenacious fine grained layer at the metal-InP interface. An energy dispersive spectrographic (EDS) analysis of the residual layer, using $\mathrm{Au}_{2} \mathrm{P}_{3}$ and eutectic $\mathrm{Au} / \mathrm{Ge}$ as standards, indicated that the layer contained $A u, G e$, and $P$ in the proportion 2:3:4. A similar analysis on a sample sintered for 60 minutes at $350 \mathrm{C}$ gave identical results, indicating that the layer is a stable end product.

Questioning whether the layer is a $\mathrm{Au}_{2} \mathrm{Ge}_{3} \mathrm{P}_{4}$ ternary or a combination of binaries such as $\mathrm{Au}_{2} \mathrm{P}_{3}$ and GeP, we subjected a previously etched sample to a second heat treatment which is known to
decompose any $\mathrm{Au}_{2} \mathrm{P}_{3}$ that is present. (16) We thus re-sintered an etched sample at $480 \mathrm{C}$ for 10 minutes, and followed this with a second chemical etch to remove any $\mathrm{Au}_{2} \mathrm{P}_{3}$ decomposition products. When an EDS analysis was performed on the double-etched sample we found no change in the composition of the residual layer. We thus conclude that the layer is indeed a ternary compound.

Because the presence of the $\mathrm{Au}_{2} \mathrm{Ge}_{3} \mathrm{P}_{4}$ ternary coincides with the measurement of low contact resistance, we suggest that it is the cause of the observed resistivity drop. It should be noted that an interfacial Au-Ge-P ternary phase has also been reported to form in sintered AuGeNi contacts containing very small amounts of Ni. (18)

The addition of $\mathrm{Ge}$ thus does two things. First, it suppresses the Au-InF metallurgical interaction. Second, it causes the phosphorus atoms that are released during stage I of the Au-InP

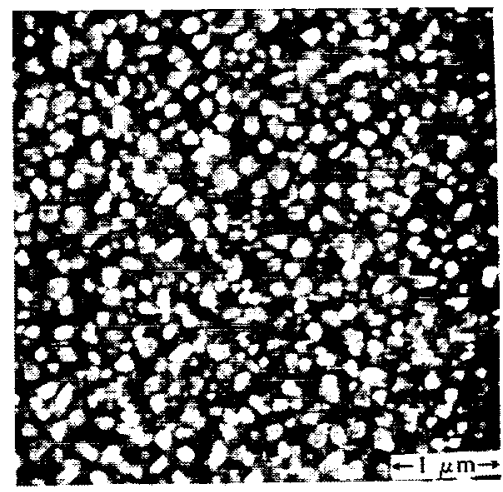

Figure 4. Residual layer remaining on InP surface after chemical etch to remove $A U$ and $A u$ alloys. 
reaction to chemically react rather than to dissipate, as is observed with Au-only contacts. (19) These two effects combine to produce an extraordinary contact system. The rate suppressing effect slows down emitter dissolution so that sintering can be performed without sacrificing emitter integrity. In addition, the presence of $G e$ induces the $P$ atoms released during stage I (which would dissipate in the absence of $\mathrm{Ge}$ ) to react rapialy with $A u$ and $G e$ to form a stable, resistance-lowering ternary at the metal-semiconductor interface. These attributes make this system a truly unique and highly useful contact system.

\section{AS-FABRICATED AU/Ge CONTACTS}

Some final comments are in order concerning the low as-fabricated value of $R_{C}$ observed in the $A u-7$ ato Ge system compared to that observed with Au-only contacts (figure l). It has previously been shown that when Au metaliization contains small amounts of additives that retard the metal-InP interaction rate (such as $A U-G a(9)$ and $A u-I n(10)$ ), the as-fabricated $R_{c}$ values are significantly lower than those measured for Au-only contacts. The suggested mechanism is that when In entry into the contacting Au is retarded, the In-to-P ratio at the metal-InP interface is increased, and the contact resistance is lowered as a result. (9) It is suggested that the same mechanism is involved here also where $\mathrm{Ge}$ additions are effective in retarding the Au-InP reaction rate.

There are a number of ways in which the addition of $\mathrm{Ge}$ (or $\mathrm{Ga}$ or In) could retard the metal-Inf reaction rate. As mentioned above, we have postulated that the metal-InP reaction rate is suppressed because $\mathrm{Ge}$ saturates the interstices of the Au lattice, preventing the entry therein of In from the InP substrate. There is evidence, however, that certain active metals, such as Ni, when placed at the metal-InP interface, directly influence the relative outdiffusion rates of In and $P$, and thus control the In-to-P atomic ratio at the interface. (20) This can be seen by comparing the as-fabricated $R_{c}$ values of the $\mathrm{Ni} / \mathrm{InP}$ system(13) (Ni being an active metal(20), with those of the Au/InP system(13) (Au being an inactive metal(20), The former values are about an order of magnitude lower than the latter.

To determine which of these mechanisms is operating when Ge is introduced into the contact system, we fabricated a number of samples where $\mathrm{Ge}$ was deposited first, in direct contact with the InP substrate, followed by Au deposition. We found the as-fabricated resistivities of these InP/Ge/Au samples to be no better than those measured for Au-only contacted samples, even though Ge is in direct contact with the InP substrate. The direct involvement of $\mathrm{Ge}$ at the metal-InP interface can thus be discounted. The evidence thus supports interstitial saturation as the mechanism that controls the (as-fabricated) In-to-P ratio (and thus the as-fabricated value of $R_{C}$ ) at the $A u(G e) / I n P$ interface.

\section{REFERENCES}

1. L.P.Erickson, A.Waseem, and G.Y.Robinson, Thin Solid Films 64, 421 (1979).

2. H.Morkoc, T.J.Drummond, and C.M.Stanchak, IEEE Trans. Electron. Dev. ED-28, 1 (1980).

3.M.J.F.O'Keefe, R.E.Miles, and

M.J.Howes, Proc. SPIE Conference on InP and Related Compounds, Norman OK, 1989, p. 361.

4. E.Kuphal, Solid St. Electron. 24, 69 (1981).

5. J.A.Del Alamo and T.Mitzutani, Solid St. Electron. 31, 1635 (1988)

6. G.Bahir, J.I.Merz, J.R.Ableson, and T.W.Sigmon, J. Electron. Mat. 16, 257 (1987).

7. A.Appelbaum, M.Robbins, and F.Schrey, IEEE Trans. Electron. Dev. ED-34, 1026 (1987).

8. P.Auvray, A.Guivarc'h, H.L.Haridon, and J.P.Mercier, Thin Solid Films 127, 39 (1985).

9. V.G.Weizer and N.S.Fatemi, J. Appl. Phys. 69, 8253 (1991).

10. N.S.Fatemi and V.G.Weizer, J.

Electron. Mat. 20, 875 (1991).

11. N.S.Fatemi and V.G.Weizer, Mat. Res.

Soc. Proc. 260, 537 (1992).

12. D.G.Ivey, R.Bruce, and G.R.Piercy, J Electron. Mat. 17,373 (1988).

13. N.S.Fatemi and V.G.Weizer, J. Appl. Phys. 73, 289 (1993).

14. A. Katz, B.E.Weir, and

W.C.Dautremont-Smith, J. Appl. Phys. 68, 1123 (1990).

15. A.Ratz, B.E.Weir, S.N.G.Chu,

P.M.Thomas, M.Soler, T.Boone, and

W.C.Dautremont-Smith, J. Appl. Phys. 67, 3872 (1990).

16. N.S.Fatemi and V.G.Weizer, J. Appl. Phys. 65, 2111 (1989).

17. A.J.Barcz, E.Kaminska, and A.

Piotrowska, Thin Solid Films 149, 251 (1987).

18. R.J.Graham and J.W.Steeds, Inst. Phys. Conf. Ser. 67, 507 (1983).

19. N.S.Fatemi and V.G.Weizer, J. Appl. Phys. 67, 1934 (1990).

20. L.J.Brillson, C.F.Brucker, A.Katnani, N.Stoffel, and G.Margaritondo, Appl. Phys. Lett. 38,784 (1981).

Work performed by N.S.F. and A.L.R. was done under contracts NAS3-25266 and NAS3-30759, respectively, with the NASA Lewis Research Center. 


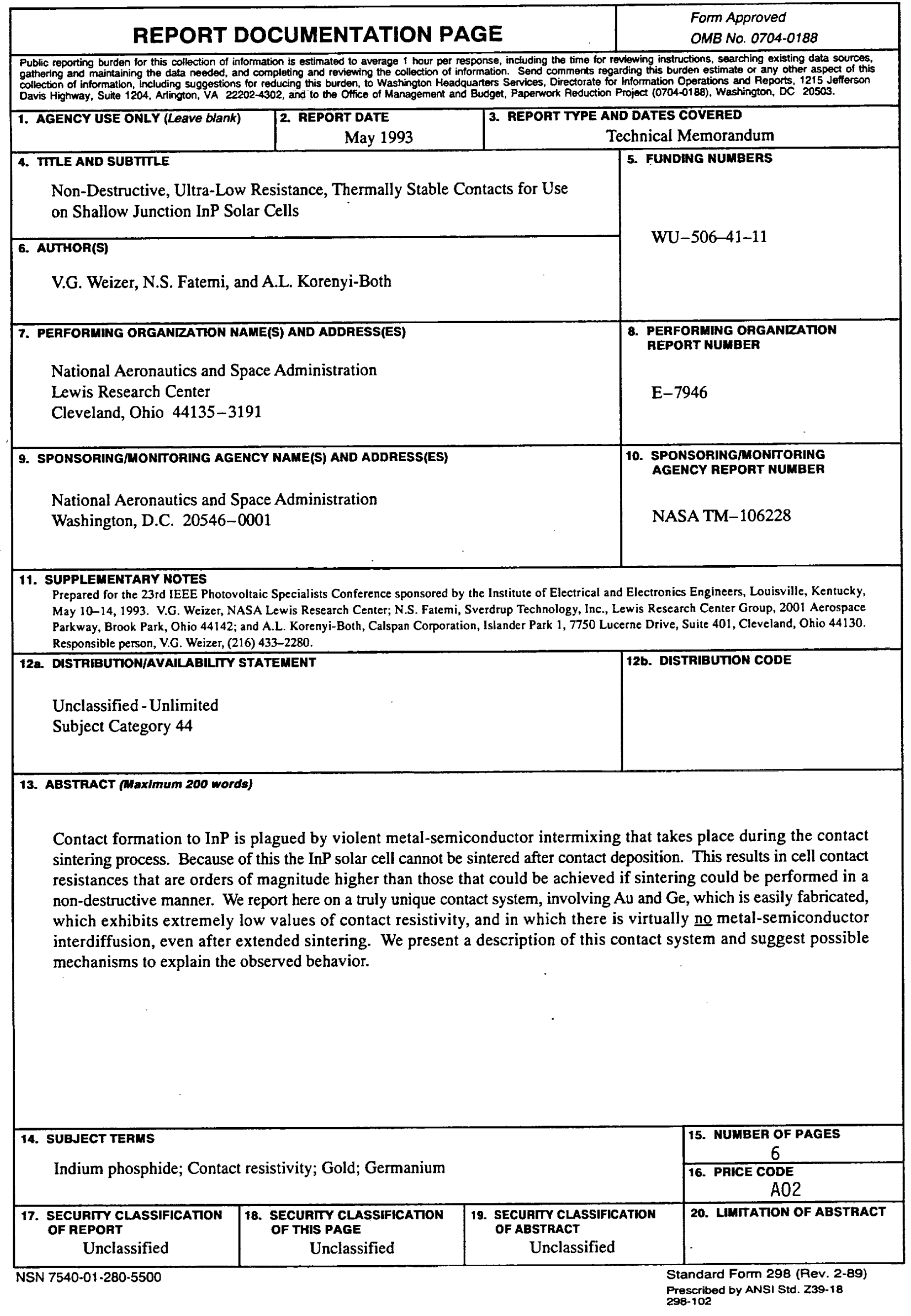




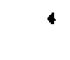

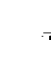

